\title{
The Coolidge Effect in male rat copulatory behavior: Failure to replicate Fisher's results'
}

SIGMUND HSIAO, University of Arizona. Tucson, Arizona 85721

Forty-eight Sprague-Dawley male rats were equally divided into three groups. Each $S$ in Group 1 was given a fresh female immediately after each ejaculation, and $15 \mathrm{~min}$ after the refractiory period half of the $S$ s were given new fresh females and the other half were interrupted by lifting and returning the same female. Group 2 was interrupted immediately after each ejaculation. Fifteen minutes after the refractory period half were given fresh females and half were interrupted. Group 3 was undisturbed immediately after ejaculation but at the $15 \mathrm{th}$ min of the refractory period half received fresh females and the other half were interrupted. Mating was observed until 45 min elapsed without male sexual responses. The results show no effect of inmediate change or the change after 15 min of the refractory period. The course of male sexual satiation was not altered by the change. Thus, in spite of the same procedure, Fisher's results $(1962)$ were not replicated.

Fisher (1962) demonstrated that when a different female rat was introduced after the male's refractory period reached 15 min the male would soon resume the copulation with the second female. Continuing the female change whenever the male reached 15 -min criterion, Fisher reported that the male ejaculated 12.4 times and achieved 85.5 intromissions compared with 6.9 ejaculations and 43.0 intromissions in the group with no female change. This phenomenon, called the Coolidge Effect, has been studied repeatedly (Beach \& Ranson, 1967; Bermant, Lott, \& Anderson, 1968; Fowler \& Whalen, 1961; Hsiao, 1965; Wilson, Kuehn, \& Beach, 1963). However, no other results even approach those which Fisher reported. The Coolidge Effect has been reported to be only about one or two extra ejaculations and the main trend of male sexual exhaustion has not been altered by the new female.

One major procedural difference between Fisher's and others' seems to be in the time of introduction of the female change. Fisher presented the lure change after $15 \mathrm{~min}$ of refractory periods while others introduced changes after $30 \mathrm{~min}$ or $45 \mathrm{~min}$. Recently, Bermant et al (1968) investigated the temporal characteristics of the female-change effect using time intervals of $0,1.5,3,4.5,6,12,18$, or $24 \mathrm{~h}$. Since they did not use a control group of no lure change, the extent of the Coolidge Effect may be difficult to assess but they reported no increase in the ejaculatory frequency for all time intervals tested. Again, a 15-min interval was not included. The present study partly replicated Fisher's procedures in an attempt to solve the problem of the discrepancy between Fisher's results and those of others.

\section{SUBJECTS ANI APPARAT LIS}

Forty-eight Sprague-Diwley males, approximately 150 days old, were housed individually in a room with airconditioning and an artificial 12-h light cycle. Testing was done during the dark phase of the cycle. Ss had previous mating experience. Food and water were available all the time except during mating tests. The lure females were ovariectomized and injected with estradiol and progesterone to induce receptivity (Hsiao, 1965). Mating was observed in a semicircular cage with glass front, described by Beach \& Jordan (1956). Incomplete, complete intromissions, and ejaculations were registered as they occurred on a moving chart of an event recorder. Thus. the number of incomplete. complete intromissions, and ejaculations, as well as ejaculatory latency, postejaculatory refractory period, could be obtained.

\section{PROCEDURE}

Subjects were divided into three groups of 16 each. Group I Ss were each given a fresh female (which had had no mating experience for at least four (ays) immediately after each ejaculation. If the male did not make any sexual attempt for $15 \mathrm{~min}$ after an ejaculation another fresh female was presented to each of eight Ss; the other half were merely interrupted. Interruption involved removal and returning the same female to control the effect of this disturbance. Group 2 was interrupted immediately after each ejaculation. When the male reached $15 \mathrm{~min}$ of postejaculatory refractory period, eight Ss were given fresh females and the others were interrupted. Group 3 was undisturbed immediately after ejaculations. But after $15 \mathrm{~min}$ of refractory periods half the Ss were given fresh females and the other half were internupted. This group exactly replicated some of Fisher's conditions.

If the male made no sexual attempt for $15 \mathrm{~min}$ aiter introduction of the new female or interruption, another female or interruption was introduced until $45 \mathrm{~min}$ elapsed without sexual responses. The male was introduced into the testing cage $5 \mathrm{~min}$ before the lure female in order to allow it to adapt to the situation.

\section{RESULTS AND DISCUSSION}

Analysis of variance using total number of incomplete intromissions, complete intromissions, ejaculations, total ejaculatory latency or total postejaculatory refractory period does not yield statistically significant differences for comparisons between the three groups and between the two subgroups.

In Table 1, Fisher's results (1962) and the results of this study are presented for purposes of comparison. The present results are the means of all groups.

In Fisher's results the number of intromissions for an ejaculation after change is higher than the comparable ejaculation with no change. The number after change is

Table 1

Trends of Mean Number of Complete Intromissions/Ejaculation Reported by Fisher and from the Present Study

\begin{tabular}{|c|c|c|c|c|c|c|c|c|c|c|c|c|c|c|}
\hline $\begin{array}{l}\text { Serial No. of } \\
\text { ejaculation }\end{array}$ & 1 & 2 & 3 & 4 & 5 & 6 & 7 & 8 & 9 & 10 & 11 & 12 & 13 & 14 \\
\hline $\begin{array}{l}\text { Fisher's study } \\
\text { No change } \\
\text { Change }\end{array}$ & $\begin{array}{c}11.5 \\
-\end{array}$ & $\begin{array}{c}5.8 \\
\cdot\end{array}$ & $\begin{array}{c}5.7 \\
\cdot\end{array}$ & $\begin{array}{c}7.0 \\
\cdot\end{array}$ & $\begin{array}{c}6.4 \\
-\end{array}$ & $\begin{array}{c}7.0 \\
(14.8)\end{array}$ & $\begin{array}{r}5.9 \\
16.3\end{array}$ & $\begin{array}{l}4.5 \\
8.6\end{array}$ & $\begin{array}{l}2.8 \\
7.2\end{array}$ & $\begin{array}{r}3.0 \\
11.0\end{array}$ & $\begin{array}{l}(1.3) \\
10.7\end{array}$ & $\begin{array}{c}1.7 \\
(7.7)\end{array}$ & $\begin{array}{l}(1.8) \\
(5.7)\end{array}$ & $\begin{array}{l}(1.2) \\
(3.2)\end{array}$ \\
\hline $\begin{array}{l}\text { Present study } \\
\text { No change } \\
\text { Change }\end{array}$ & $\begin{array}{c}7.9 \\
-\end{array}$ & $\begin{array}{c}4.4 \\
-\end{array}$ & $\begin{array}{c}4.6 \\
-\end{array}$ & $\begin{array}{c}5.4 \\
(1.0)\end{array}$ & $\begin{array}{c}5.8 \\
(7.0)\end{array}$ & $\begin{array}{c}5.1 \\
(3.8)\end{array}$ & $\begin{array}{c}3.3 \\
(4.2)\end{array}$ & & & & & & & \\
\hline
\end{tabular}

Note: Numbers in parentheses denote fewer than 9 cases. 